\title{
Simvastatin improves cerebrovascular injury caused by ischemia-reperfusion through NF-kB-mediated apoptosis via MyD88/TRIF signaling
}

\author{
ZHIYING CHEN, YUANYUAN XIANG, BING BAO, XIANGBIN WU, \\ ZHONGBIN XIA, JIANYOU YOU and HONGBING NIE
}

Department of Neurology, Affiliated Hospital of Jiujiang University, Jiujiang, Jiangxi 332000, P.R. China

Received July 6, 2017; Accepted May 2, 2018

DOI: $10.3892 / \mathrm{mmr} .2018 .9337$

\begin{abstract}
Cerebrovascular injury is the most prevalent human cerebrovascular disease and frequently results in ischemic stroke. Simvastatin may be a potential therapeutic agent for the treatment of patients with cerebrovascular injury. The present study aimed to investigate the efficacy of and the potential mechanisms regulated by simvastatin in a rat model of ischemia-reperfusion (I/R)-induced cerebrovascular injury. Cerebrovascular injury model rats were established and were subsequently treated with simvastatin or a vehicle control following I/R injury. Cell damage, neurological functions and neuronal apoptosis were examined, as well as the nuclear factor $(\mathrm{NF})-\kappa \mathrm{B}$-mediated myeloid differentiation primary response protein 88 (MyD88)/toll-interleukin-1 receptor domain-containing adapter molecule 1 (TRIF) signaling pathway following simvastatin treatment. The results of the present study demonstrated that simvastatin treatment led to a reduction in cell damage, improvement of neurological functions and decreased neuronal apoptosis compared with vehicle-treated I/R model rats, 14 days post-treatment. In addition, simvastatin treatment reduced cerebral water content and blood-brain barrier disruption in cerebrovascular injury induced by $I / R$. The results also revealed that simvastatin treatment inhibited neuronal apoptosis via the NF- $\mathrm{B}$-mediated MyD88/TRIF signaling pathway. In conclusion, simvastatin treatment may reduce I/R-induced neuronal apoptosis via inhibition of the NF- $\kappa \mathrm{B}$-mediated MyD88/TRIF signaling pathway.
\end{abstract}

Correspondence to: Professor Hongbing Nie, Department of Neurology, Affiliated Hospital of Jiujiang University, 57 Xunyang East Road, Jiujiang, Jiangxi 332000, P.R. China

E-mail: niehongbingprof@163.com

Key words: simvastatin, cerebrovascular injury, ischemia-reperfusion, nuclear factor $-\kappa \mathrm{B}$, myeloid differentiation primary response protein MyD88, toll-interleukin-1 receptor domain-containing adapter molecule 1

\section{Introduction}

Ischemic cerebrovascular disease is the most common cause of cerebrovascular-related mortality (1). Previous studies have demonstrated that ischemia-reperfusion (I/R)-induced cerebrovascular injury may result in cerebral infarct, neurological dysfunction and neuronal cell apoptosis $(2,3)$. It has been widely recognized that neuronal apoptosis serves important roles in I/R-induced cerebrovascular injury (4-6). Inhibition of nuclear factor (NF) $\kappa \mathrm{B}$ was reported to increase neuronal apoptosis, which may represent a potential therapeutic target for the treatment of neurodegenerative disorders and diseases $(7,8)$. In addition, previous studies have revealed that the myeloid differentiation primary response protein MyD88 (MyD88) signaling pathway is associated with cellular apoptosis through the regulation of oxidative stress $(9,10)$. Furthermore, previous studies on the mechanisms of the toll-interleukin-1 receptor domain-containing adapter molecule 1 (TRIF)-induced $N F-\kappa B$ activation and apoptosis pathways have suggested that $\mathrm{NF}-\kappa \mathrm{B}$ activation is important in the process of apoptosis (11). Therefore, the present study aimed to investigate whether NF- $\kappa \mathrm{B}$ activation induces neuronal apoptosis via the MyD88/TRIF signaling pathway in a rat model of I/R-induced cerebrovascular injury.

Simvastatin is a statin drug that is used to regulate blood cholesterol levels and to prevent the development of cardiovascular and cerebrovascular diseases, resulting from decreased 3-hydroxy-3-methylglutaryl coenzyme A reductase activity $(12,13)$. It has been demonstrated that when administered for 1 week following cerebral injury, a combination of simvastatin and atorvastatin improves neurological recovery, decreases tissue loss and increases neurogenesis (14). Furthermore, systemic simvastatin was reported to rescue retinal ganglion cells from optic nerve injury by suppressing NF- $\kappa \mathrm{B}$ activation (15). However, it has also been demonstrated that simvastatin may inhibit the mevalonate cascade to induce apoptosis in neuronal cells $(16,17)$. Therefore, the present study investigated the efficacy of simvastatin to reduce neuronal apoptosis in a rat model of I/R-induced cerebrovascular injury, as well as intracellular levels of $\mathrm{NF}-\kappa \mathrm{B}$ activation in ischemic tissue. In addition, whether decreased $\mathrm{NF}-\kappa \mathrm{B}$ expression attenuated brain damage and sustained 
improvement in neurological outcomes was investigated. The molecular mechanism underlying simvastatin-mediated MyD88/TRIF/NF- $\kappa \mathrm{B}$ signaling were investigated using neurons isolated from cerebrovascular injury model rats.

\section{Materials and methods}

Ethics statement. The present study was performed in accordance with the recommendations outlined in the Guide for the Care and Use of Laboratory Animals and in accordance with the National Institutes of Health (Bethesda, MD, USA), and was approved by the Committee on the Ethics of Affiliated Hospital of Jiujiang University (Jiujiang, China; 20160214AHJUN3).

Establishment I/R-induced cerebrovascular injury rat model. Male 6-8 week old Sprague-Dawley rats $(n=20$; weight, 290-320 g) were purchased from Shanghai SLAC Laboratory Animal Co., Ltd. (Shanghai, China). All rats were housed in a temperature-controlled facility at $23 \pm 1^{\circ} \mathrm{C}$, a relative humidity of $50 \pm 5 \%$ and with a 12 -h light/dark cycle, with free access to food and water. The rat model of cerebrovascular injury was established using a modified I/R method (18); rats received right middle cerebral artery occlusion for $90 \mathrm{~min}$ and reperfusion by withdrawal of the filament at $37^{\circ} \mathrm{C}$ during surgery and post-surgery. I/R model rats were randomly divided into 2 groups ( $\mathrm{n}=6 /$ group) and each received an intravenous injection of either simvastatin (I/R + simvastatin group; $10 \mathrm{mg} / \mathrm{kg} / \mathrm{day}$; Sigma-Aldrich; Merck KGaA, Darmstadt, Germany) or the same volume of PBS (I/R group) (19). Sham-operated rats received surgery without right middle cerebral artery occlusion and were used as a control (Sham group; $n=6$ ). The treatments were administered daily for 14 days.

Protein overexpression. Neuronal cells were isolated from mice in the three experimental groups as previously

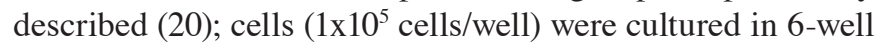
plates until $85 \%$ confluence, the medium was removed and plates were washed three times with PBS. Neuronal cells were transfected with 100 pmol pLentivirus-NF- $\kappa$ B $(\mathrm{pNF}-\kappa \mathrm{B})$, pLentivirus-MyD88 (pMyD88), pLentivirus-TRIF (pTRIF) or pLentivirus empty vector (control; Thermo Fisher Scientific, Inc., Waltham, MA, USA) using Lipofectamine ${ }^{\circledR} 2000$ (Sigma-Aldrich; Merck $\mathrm{KGaA}$ ) for $48 \mathrm{~h}$ at $37^{\circ} \mathrm{C}$, according to the manufacturer's protocol. Cells overexpressing $\mathrm{NF}-\kappa \mathrm{B}$, MyD88 or TRIF were treated with simvastatin $(2 \mathrm{mg} / \mathrm{ml}$; Sigma-Aldrich; Merck KGaA) for $12 \mathrm{~h}$ at $37^{\circ} \mathrm{C}$ for further analysis. $\mathrm{NF}-\kappa \mathrm{B}, \mathrm{MyD} 88$ and TRIF mRNA expression levels were detected by polymerase chain reaction (PCR), as previously described (21). PCR was performed using PCR cloning kit (cat. no. K270040; Thermo Fisher Scientific, Inc.). Total RNA was extracted with a RNAeasy Mini kit (Qiagen Sciences, Inc., Gaithersburg, MD, USA). cDNAs were synthesized with ReverTra Ace-a- ${ }^{\text {TM }}$ RT kit (Toyobo Life Science, Osaka, Japan) at $42^{\circ} \mathrm{C}$ for $2 \mathrm{~h}$. The sequences of the primers were as follows: NF- $\kappa$ B forward, 5'-TAAGTGGGG CATCAAAGGA-3' and reverse, 5'-TGGGAAAAGAGCCAA GAGAA-3'; MyD88 forward, 5'-GACCCAGCATTGGGC-3' and reverse, 5'-TCAGGGCAGGGACAAGGCCTTGGC AAG-3'; TRIF forward, 5'-CTGCTTGGMGACTTCCTG
AC-3' and reverse, 5'-GTGGATGGTSCCGTTACTGAG-3'; $\beta$-actin forward, 5'-CGGAGTCAACGGATTTGGTC-3' and reverse, 5'-AGCCTTCTCCATGGTCGTGA-3'. The qPCR thermocycling conditions were as follows: $95^{\circ} \mathrm{C}$ for $2 \mathrm{~min}$, 35 cycles of $95^{\circ} \mathrm{C}$ for $20 \mathrm{sec}, 55.8^{\circ} \mathrm{C}$ for $20 \mathrm{sec}$ and $72^{\circ} \mathrm{C}$ for $20 \mathrm{sec}$, followed by a final extension at $72^{\circ} \mathrm{C}$ for $5 \mathrm{~min}$. The results were expressed as the fold difference in expression compared with the housekeeping gene ( $\beta$-actin) (22). Subsequent experiments were performed $72 \mathrm{~h}$ following transfection.

Western blot analysis. Neuronal cells were isolated from rats 14 days following I/R-induced cerebrovascular injury (23). Cells and tissues were lysed at $4^{\circ} \mathrm{C}$ for $10 \mathrm{~min}$ in mammalian protein extraction reagent (PER) or tissue PER reagent, respectively (Thermo Fisher Scientific, Inc.). Protein concentration was determined with a bicinchoninic acid protein assay kit (Thermo Fisher Scientific, Inc). Protein samples $(20 \mu \mathrm{g})$ were separated by $12.5 \%$ SDS-PAGE and transferred to nitrocellulose membranes. The membranes were incubated in blocking buffer (5\% non-fat milk) at $4^{\circ} \mathrm{C}$ for $12 \mathrm{~h}$. The primary rabbit antibodies used included: NF- $\kappa \mathrm{Bp} 65$ (1:1,200; cat. no. ab16502), phosphorylated-NF-кB (1:1,200; cat. no. ab86299), P53 (1:1,200; cat. no. ab26), matrix metalloproteinase-9 (MMP-9; 1:1,000; cat. no. ab54230), caspase-3 (1:1,200; cat. no. ab2171), B-cell lymphoma 2 (Bcl-2; 1:1,000; cat. no. ab692), MyD88 (1:500; cat. no. ab2068), TRIF (1:500; cat. no. ab13810) and $\beta$-actin (1:500; cat. no. ab8226; all Abcam, Cambridge, UK). The membranes were subsequently incubated with horseradish peroxidase-conjugated anti-rabbit immunoglobulin G secondary antibody (1:5,000; cat. no. 172-1033-SDS; Bio-Rad Laboratories, Inc., Hercules, CA, USA) for $12 \mathrm{~h}$ at $4^{\circ} \mathrm{C}$, and protein bands were detected using an Enhanced Chemiluminescence assay system (Roche Diagnostics, Basel, Switzerland). Densitometric quantification of the immunoblot data was performed using the software of Quantity-One version 1.1 (Bio-Rad Laboratories, Inc.) and protein expression was normalized to $\beta$-actin.

Terminal deoxynucleotidyl-transferase-mediated dUTP nick end labeling (TUNEL) assay. Apoptotic neuronal cells in the hippocampus of I/R model rats were analyzed using the DeadEnd Colorimetric TUNEL System (Promega Corporation, Madison, WI, USA) according to the manufacturer's instructions. Cells were fixed with $10 \%$ paraformaldehyde for $30 \mathrm{~min}$ at $37^{\circ} \mathrm{C}$. Cells were subsequently washed with PBS and stained with TUNEL reagent for $30 \mathrm{~min}$ at $37^{\circ} \mathrm{C}$, followed by DAPI staining for $15 \mathrm{~min}$ at $37^{\circ} \mathrm{C}$. Cell damage was indicated by the TUNEL-positive cell number. The cells were analyzed using an Olympus Bx51 fluorescence microscope (Olympus Corporation, Tokyo, Japan) in six random fields of view.

Behavioral tests. Three different behavioral tests were performed, including neurological deficit, forelimb foot-fault and open-field tests. Neurological deficit score were determined using a scoring system (24). The forelimb foot-fault-placing test was used to examine forelimb function, as described previously (25). Open-field tests (rearing time and locomotor activity) were performed to investigate the efficacy of simvastatin administration on I/R injury, as previously described (26). 
A

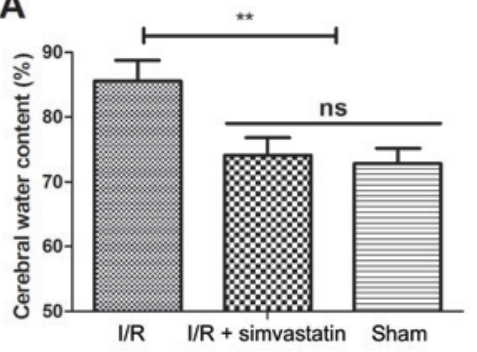

B

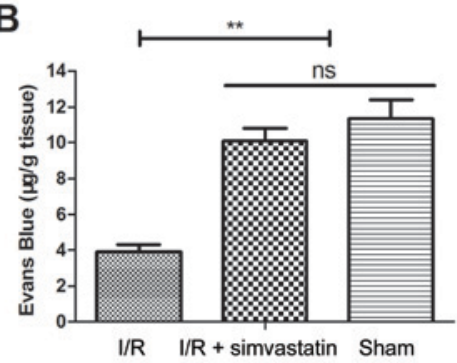

Figure 1. Simvastatin attenuates CWC and BBB disruption in I/R injury rats. (A) Simvastatin treatment significantly decreased the CWC of I/R rats compared with the untreated I/R group. (B) Simvastatin treatment improved BBB disruption in I/R rats. ${ }^{* *} \mathrm{P}<0.01 \mathrm{vs}$. I/R group. BBB, blood brain barrier; $\mathrm{CWC}$, cerebral water content; ns, not significant; I/R, ischemia-reperfusion.

A

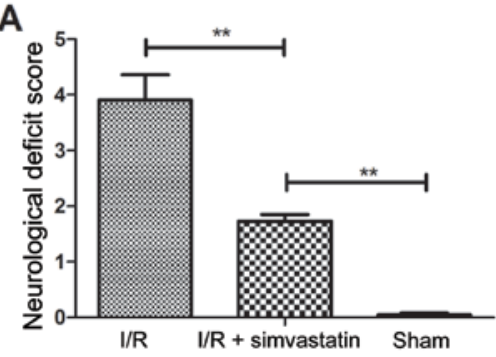

C

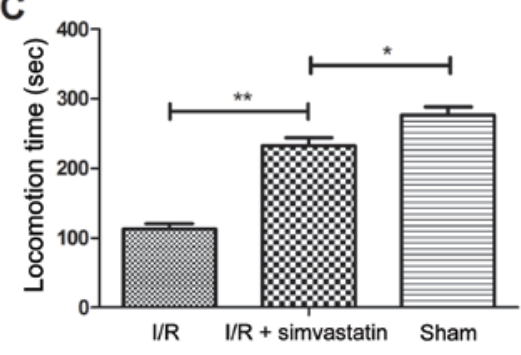

B

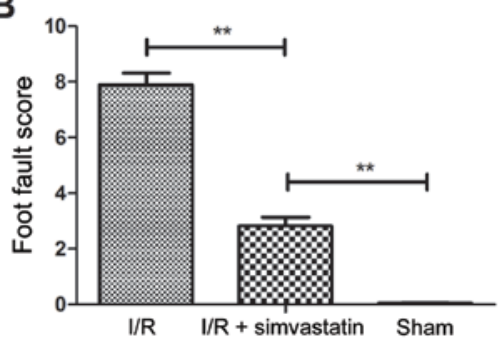

D

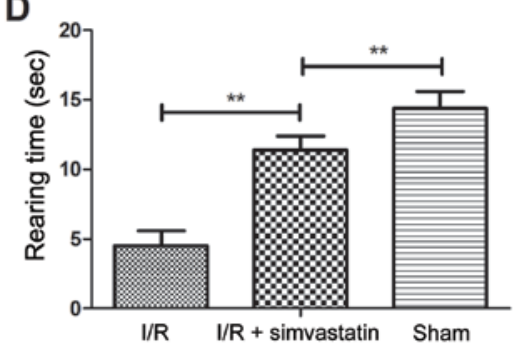

Figure 2. Simvastatin improves cognitive function in I/R rats. (A) Simvastatin treatment significantly decreased neurological deficit scores compared with the vehicle-treated I/R rats. (B) Simvastatin treatment significantly improved functional deficits of the left forelimb compared with the vehicle-treated I/R rats. (C) Simvastatin treatment increased ipsilateral cerebral hemisphere volume. (D) Simvastatin treatment significantly improved motor function in I/R rats. ${ }^{*} \mathrm{P}<0.05,{ }^{* *} \mathrm{P}<0.01 . \mathrm{I} / \mathrm{R}$, ischemia-reperfusion.

Analysis of cerebral water content (CWC). Brain tissues were obtained from experimental mice as previously described (27), and the brain water content of $\mathrm{I} / \mathrm{R}$ model rats was determined following 14 days treatment with simvastatin, as previously described (28). Rat brains were isolated and divided into two hemispheres. The two hemispheres were weighed using an electronic analytical balance to obtain the wet weight. Brain tissues were dried in an electric oven at $100^{\circ} \mathrm{C}$ for $24 \mathrm{~h}$ and weighed to determine the brain water content using the following formula: Water content $(\%)=[$ (wet weight-dry weight)/wet weight] $\times 100$.

Quantitative analysis of blood-brain barrier (BBB) permeability. BBB leakage was investigated using previously described protocol (29), with a slight modification. The experimental rats (simvastatin or saline groups; $n=4$ in each group) were intravenously administered $100 \mu 15 \%$ Evan's blue 14 days following I/R-induced injury. A total of $2 \mathrm{~h}$ following Evan's blue injection, cardiac perfusion was performed using $200 \mathrm{ml}$ of saline under deep anesthesia to clear the cerebral circulation of Evan's blue. The brain was then isolated using a freezing microtome. Following this, the two hemispheres were homogenized in $750 \mu \mathrm{l}$ of $\mathrm{N}, \mathrm{N}$-dimethylformamide. Quantitative analysis of BBB permeability was determined $(620 \mathrm{~nm}$ and $680 \mathrm{~nm})$ using ultraviolet spectrophotometer (DR6000; Hach Company, Loveland, CO, USA) via analysis of Evan's blue content.

Statistical analysis. Data were presented as mean \pm standard deviation of at least three replicated experiments. All data were analyzed using SPSS 13.0 software (SPSS, Inc., Chicago, IL, USA). Significant differences were analyzed using one-way analysis of variance followed by Tukey's honest significant difference test. $\mathrm{P}<0.05$ was considered to indicate a statistically significant difference.

\section{Results}

Simvastatin improves cerebral water content and BBB disruption in $I / R$ model rats. To investigate the effects of simvastatin on $I / R$ injury, a rat model of cerebrovascular injury was established. Rats in the I/R + simvastatin and Sham-operated groups exhibited a significantly lower CWC compared with the untreated I/R rats (Fig. 1A); no significant difference in CWC 
A
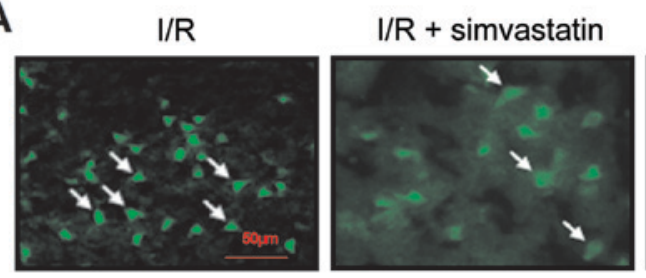

B

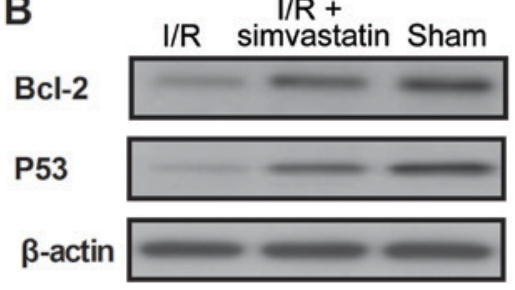

Sham
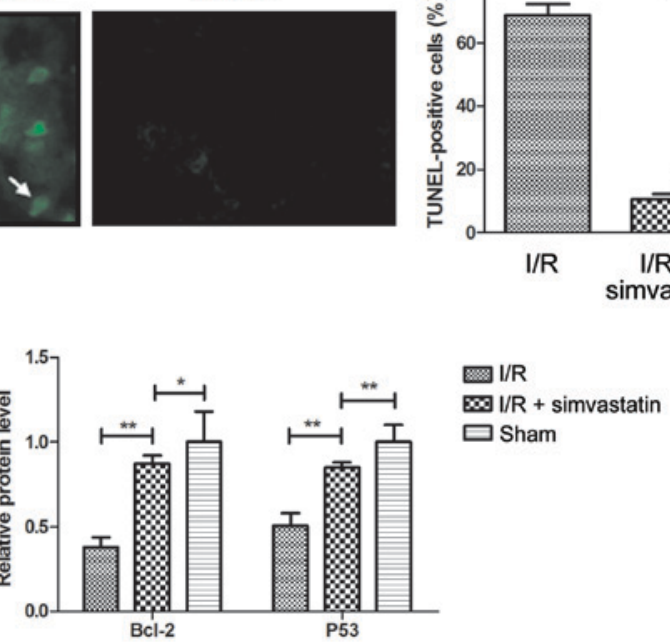

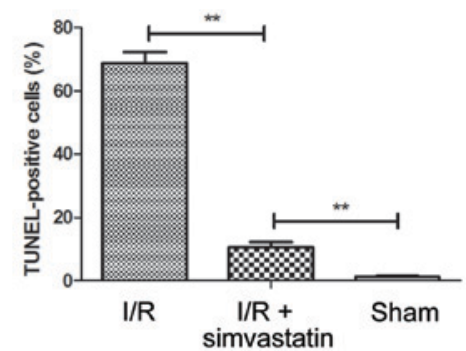

imvastatin
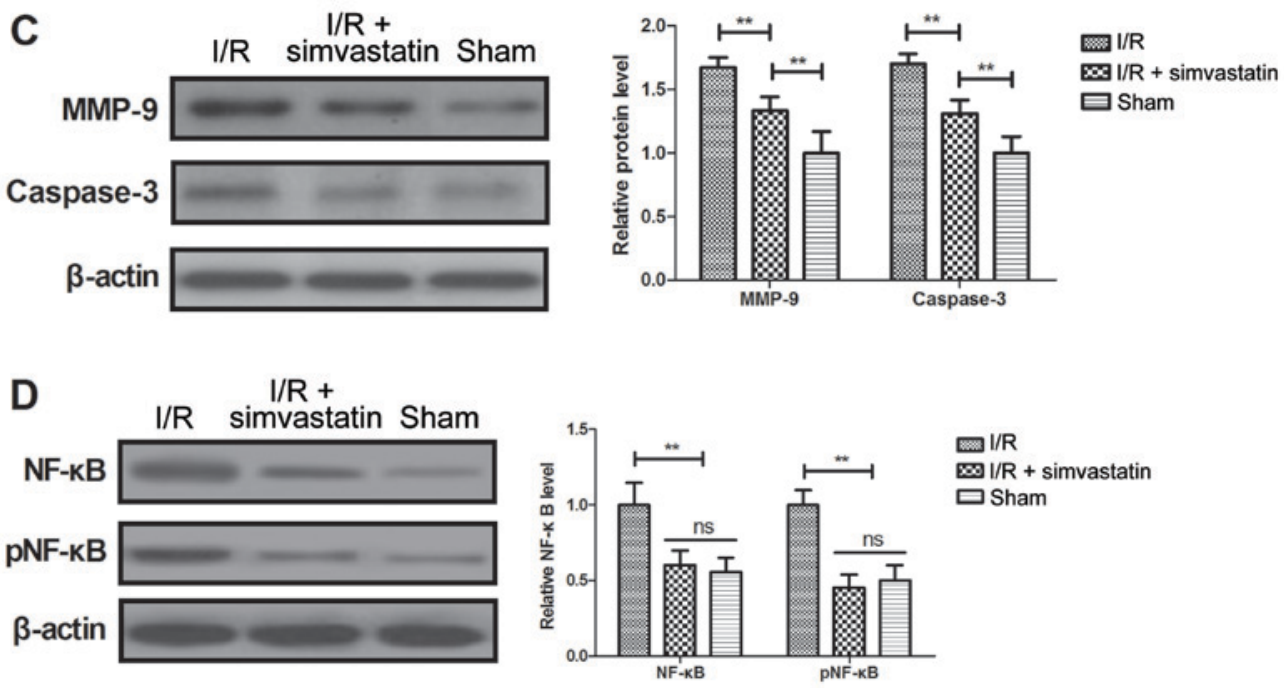

Figure 3. Simvastatin decreases I/R injury-induced neuronal apoptosis. (A) Simvastatin treatment significantly decreased the number of terminal deoxynucleotidyl-transferase-mediated dUTP nick end labeling-positive neuronal cells compared with vehicle-treated I/R injury rats. (B) Simvastatin treatment significantly increased Bcl-2 and P53 expression levels in I/R rat neurons. (C) Simvastatin treatment significantly decreased MMP-9 and caspase-3 level in neurons following I/R injury. (D) Simvastatin treatment decreased I/R-induced NF- $\kappa \mathrm{B}$ expression compared with vehicle-treated $\mathrm{I} / \mathrm{R}$ rats. $\mathrm{P}<0.05$, ${ }^{* *} \mathrm{P}<0.01$. Bcl-2, B-cell lymphoma 2; I/R, ischemia-reperfusion; MMP-9, matrix metalloproteinase-9; NF- $\mathrm{B}$, nuclear factor- $\kappa \mathrm{B}$; ns, not significant; p, phosphorylated.

was detected between the $\mathrm{I} / \mathrm{R}+$ simvastatin rats and the Sham rats. Furthermore, the results demonstrated that simvastatin treatment significantly increased BBB disruption in cerebrovascular injury rats compared with the I/R group (Fig. 1B). These results suggested that simvastatin treatment significantly attenuated CWC and BBB disruption in I/R injury rats.

Simvastatin improves cognitive performance in $I / R$ injury rats. The neurological effects of simvastatin in ischemic rats were also investigated. Treatment with simvastatin significantly decreased neurological deficit scores compared with vehicle-treated I/R model rats (Fig. 2A). The results of the foot-fault-placing test revealed that simvastatin significantly improved functional deficits of the left forelimb in simvastatin-treated I/R rats compared with vehicle-treated I/R rats (Fig. 2B). Furthermore, ipsilateral cerebral hemisphere volume and motor functions were significantly improved in ischemic rats following administration of simvastatin; I/R + simvastatin rats exhibited significantly enhanced open-field activities, such as locomotion and rearing behavior, compared with the vehicle-treated I/R rats (Fig. $2 \mathrm{C}$ and $\mathrm{D}$ ). These results suggest that simvastatin exhibited beneficial effects regarding I/R injury-induced behavioral dysfunction.

Simvastatin decreases I/R injury-induced neuronal apoptosis. The effects of simvastatin administration on neuronal apoptosis in $\mathrm{I} / \mathrm{R}$ model rats were investigated. The results demonstrated that the percentage of TUNEL-positive neuronal cells was significantly decreased in $\mathrm{I} / \mathrm{R}+$ simvastatin rats compared with $\mathrm{I} / \mathrm{R}$ rats (Fig. 3A). Simvastatin treatment significantly increased Bcl-2 and P53 protein expression levels in $\mathrm{I} / \mathrm{R}$ rats compared with expression levels in the untreated $I / R$ group (Fig. 3B). MMP-9 and caspase-3 expression levels were significantly decreased in $\mathrm{I} / \mathrm{R}+$ simvastatin rats compared with untreated I/R rats (Fig. 3C). Furthermore, simvastatin 
A

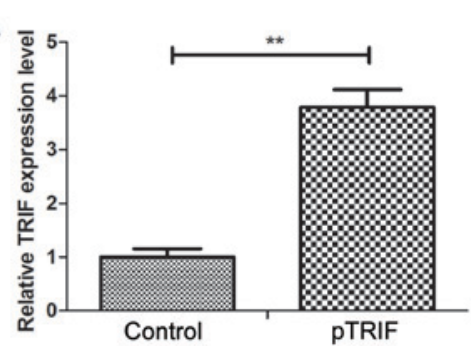

B

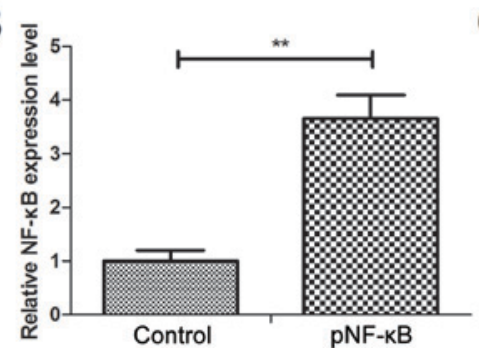

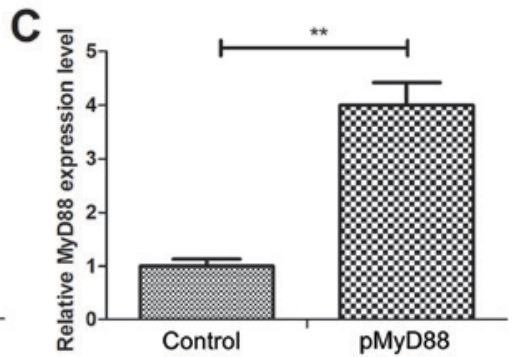

Figure 4. Neuronal cells were successfully transfected with pTRIF, pNF-кB and pMyD88. (A-C) The mRNA expression levels of TRIF, NF-kB and MyD88 were significantly increased in neuronal cells transfected with (A) pTRIF, (B) NF-kB or (C) MyD88, respectively. ${ }^{* *} \mathrm{P}<0.01$. MyD88, myeloid differentiation

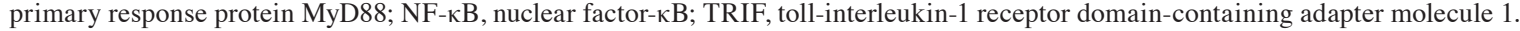

treatment significantly lowered the I/R-induced NF- $\kappa \mathrm{B}$ and phosphorylated-NF- $\mathrm{B}$ protein expression levels compared with vehicle-treated I/R rats (Fig 3D). These results suggested that simvastatin administration decreased I/R injury-induced neuronal apoptosis.

Simvastatin reduces neuronal apoptosis via suppression of NF- $\kappa B$-regulated MyD88/TRIF signaling pathway. To determine the mechanism of simvastatin-inhibited neuronal apoptosis, the $\mathrm{NF}-\kappa \mathrm{B}$ signaling pathway induced by MyD88/TRIF in cultured neuronal cells was investigated. Cells transfected with pTRIF, $\mathrm{pNF}-\kappa \mathrm{B}$ or pMyD88 were confirmed to exhibit a significant increase in the levels of TRIF, $\mathrm{NF}-\kappa \mathrm{B}$ and MyD88 mRNA expression, respectively, compared with the control cells (Fig. 4A-C). In I/R + simvastatin rat neuronal cells, MyD88 and TRIF protein expression levels were significantly reduced compared with untreated I/R rats (Fig. 5A). MyD88 overexpression suppressed pMyD88-simvastatin-inhibited (pMyD88-SV) TRIF and NF- $\kappa$ B expression in neuronal cells, compared with the control cells (Fig. 5B). TRIF overexpression also suppressed pTRIF-SV NF- $\kappa$ B expression in neuronal cells (Fig. 5C). MyD88 or TRIF overexpression increased neuronal apoptosis and canceled simvastatin-inhibited neuronal apoptosis compared with control cells (Fig. 5D and $\mathrm{E})$. NF- $\mathrm{KB}$ overexpression also increased neuronal apoptosis and canceled simvastatin-inhibited neuronal apoptosis compared with control cells (Fig. 5F). These results suggested that administration of simvastatin suppresses neuronal apoptosis via NF- $\kappa \mathrm{B}$ activation regulated by the MyD88/TRIF signaling pathway.

\section{Discussion}

It has previously been demonstrated that simvastatin exhibits anti-apoptotic effects and increases neuronal excitability in the hippocampus $(30,31)$. Previous studies have revealed that the MyD88/TRIF signaling pathway is involved in NF- $\kappa \mathrm{B}$ activation, which may regulate apoptosis in inflammatory injury in intracerebral hemorrhage-induced neurological deficits (32). In the present study, whether simvastatin exhibited protective effects to neurons against apoptosis through the regulation of MyD88/TRIF/NF- $\kappa$ B signaling was investigated. The results suggested that simvastatin treatment significantly improved CWC and BBB disruption and attenuated neuronal apoptosis via suppression of the NF- $\kappa \mathrm{B}$-mediated MyD88/TRIF signaling pathway in $\mathrm{I} / \mathrm{R}$ model rats.
A previous study demonstrated that simvastatin may be a therapeutic agent for treatment against ischemic brain injury, and the protective effects of simvastatin may be partially due to its ability to improve microvascular reperfusion. (33). The present study demonstrated that simvastatin treatment not only improved neurological deficit, but also improved motor function of $\mathrm{I} / \mathrm{R}$ rats. HMG $\mathrm{CoA}$ reductase inhibitors were previously reported to attenuate ischemic brain injury in Wistar rats through the suppression of neuronal oxidative stress (34). The results of the present study demonstrated that simvastatin administration significantly reduced the levels of I/R-induced neuronal apoptosis. Similarly, Hadi et al (35) suggested that administration of simvastatin attenuates myocardial I/R injury in rats via suppression of apoptosis. In the present study, it was demonstrated that simvastatin decreased the number of TUNEL-positive neuronal cells in $I / R$ rats compared with vehicle-treated $I / R$ rats. It was recently reported that a combinatory treatment of simvastatin with tissue-type plasminogen activator is safe for patients with acute ischemic stroke (36). The present study demonstrated that simvastatin reduced neuronal apoptosis through the suppression of the NF- $\mathrm{B}$-mediated MyD88/TRIF signaling pathway. Numerous studies have demonstrated that simvastatin is beneficial in the treatment of brain injury via different signaling pathways (37-40). A previous study demonstrated that vascular recovery was enhanced by administration of simvastatin following experimental cerebral injury, as revealed by magnetic resonance imaging and histological investigation (41). The present study revealed that simvastatin exhibited an important neuroprotective role against I/R injury-induced neuronal apoptosis via suppression neuronal apoptosis and attenuation of neurological dysfunctions. Zhao et al (42) demonstrated that simvastatin protects human osteosarcoma cells from oxidative stress-induced apoptosis by downregulating caspase- 3 and caspase- 9 activation, as well as upregulating of $\mathrm{Bcl}-2$ expression. Suppression of MMP-9 expression was also reported to reduce neuronal apoptosis following I/R injury (43). In the present study, it was revealed that simvastatin treatment may have suppressed neuronal apoptosis via a NF- $\mathrm{B}$-mediated decrease in MMP-9 and caspase-3 expression in I/R rats. The results suggested that simvastatin may inhibit I/R injury-induced $\mathrm{NF}-\kappa \mathrm{B}$ expression, which may contribute to the suppression of neuronal apoptosis.

Inhibition of $\mathrm{NF}-\kappa \mathrm{B}$ signaling may suppress apoptosis and promote neuronal differentiation of medulloblastoma 

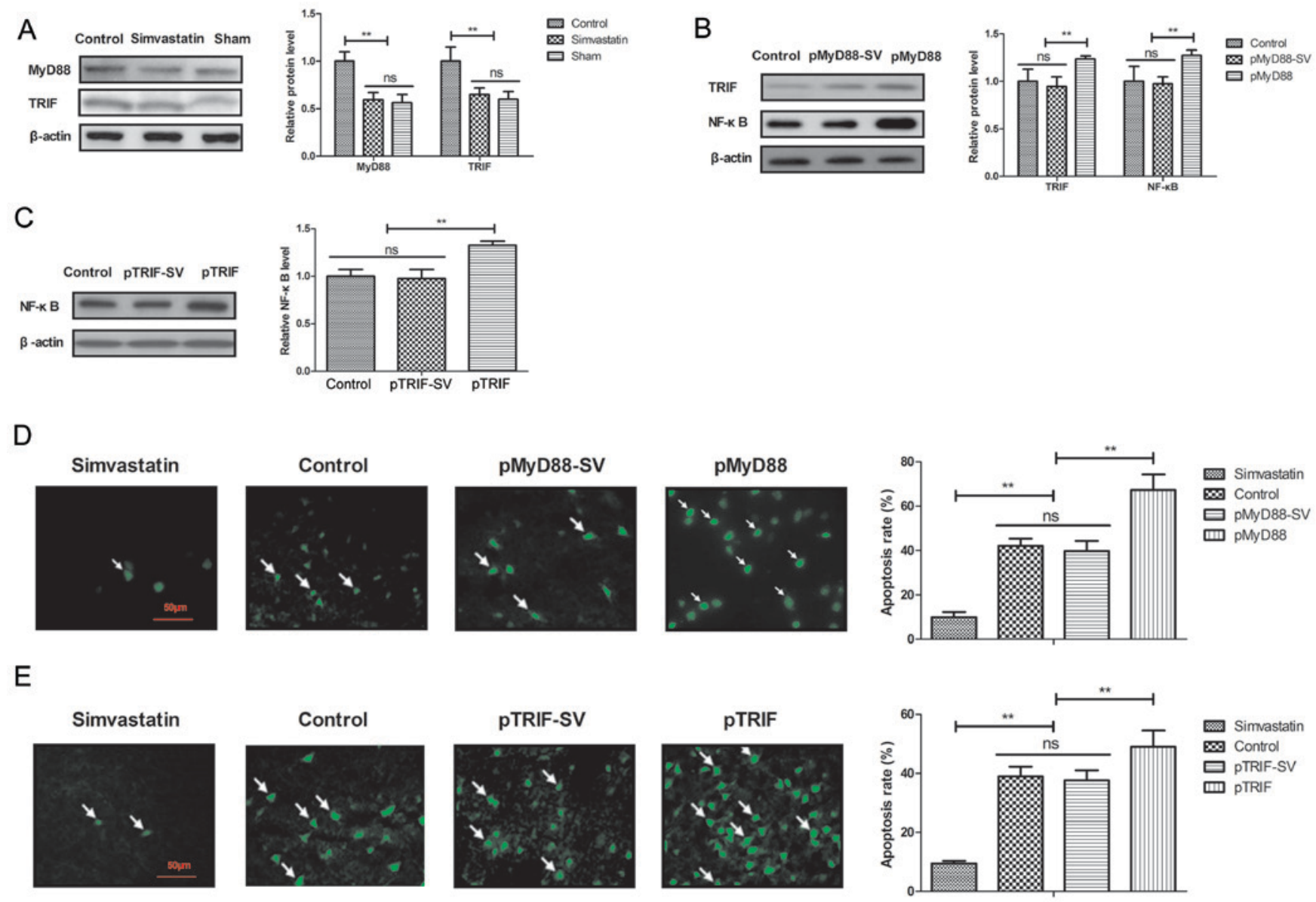

F
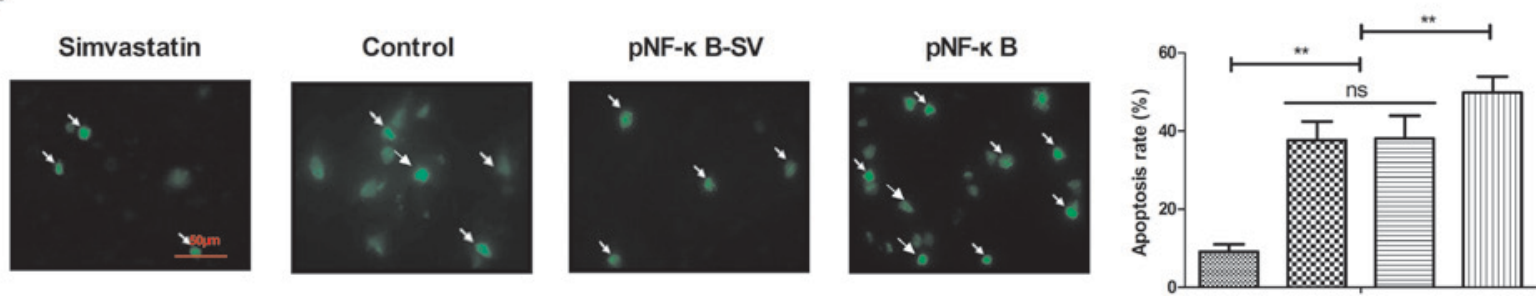

Simvastatin

$\infty$ Control

曰 PNF-K B-SV

四 $\mathrm{pNF}-\mathrm{B}$

Figure 5. Simvastatin reduces neuronal apoptosis by suppressing NF-kB-regulated MyD88/TRIF signaling pathway. (A) Simvastatin treatment downregulated MyD88 and TRIF NF-kB protein expression levels in neuronal cells compared with neuronal cells obtained from untreated I/R rats. (B) MyD88 overexpression

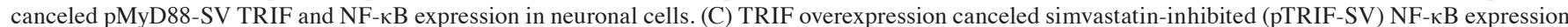
in neuronal cells. (D) MyD88 or (E) TRIF overexpression increases neuronal apoptosis and cancels simvastatin-inhibited neuronal apoptosis of neural cells. (F) NF- $\mathrm{kB}$ overexpression increases neuronal apoptosis and cancels simvastatin-inhibited neuronal apoptosis of neural cells. ${ }^{* *} \mathrm{P}<0.01$. MyD88, myeloid differentiation primary response protein MyD88; NF- $\mathrm{B}$, nuclear factor- $\mathrm{kB}$; ns, not significant; p, pLentivirus; SV, simvastatin; TRIF, toll-interleukin-1 receptor domain-containing adapter molecule $1 ; \mathrm{I} / \mathrm{R}$, ischemia-reperfusion.

cells (44). Cates et al (45) demonstrated that MyD88 overexpression stimulates NF- $\mathrm{\kappa B}$ activation and apoptosis. Results of the present study demonstrated that simvastatin downregulated NF- $\kappa \mathrm{B}$ and MyD88 expression in neurons isolated from $\mathrm{I} / \mathrm{R}$ model rats. TRIF-induced apoptosis is dependent on NF- $\kappa B$ activity (46). The present study results demonstrated that simvastatin treatment may suppress I/R-induced neuronal apoptosis through inhibition of the NF- $\kappa B$-mediated MyD88/TRIF signaling pathway, which may have led to the, improvements in neurological assessment performance and motor function. These effects were sustained for 14 days post-I/R.

Inconclusion, administration of simvastatinexhibited neuroprotective effects by disrupting the MyD88/TRIF-mediated NF- $\mathrm{BB}$ pathway following I/R-induced cerebrovascular injury.
Therefore, the NF- $\kappa \mathrm{B}$-mediated MyD88/TRIF signaling pathway may represent a potential therapeutic target for the treatment of cerebrovascular injury. These results suggested that simvastatin may represent a novel therapeutic agent for the prevention and treatment of I/R-induced cerebrovascular injury.

\section{Acknowledgements}

Not applicable.

\section{Funding}

This study was supported by Natural Science Foundation of China 81660209. 


\section{Availability of data and materials}

The datasets used and/or analyzed during the current study are available from the corresponding author on reasonable request.

\section{Authors' contributions}

ZC performed the experiments. YX, BB, XW, ZX, JY and HN analyzed the data. HN designed the study. All authors read and approved the final manuscript.

\section{Ethics approval and consent to participate}

The present study was performed in accordance with the recommendations outlined in the Guide for the Care and Use of Laboratory Animals and in accordance with the National Institutes of Health, and was approved by the Committee on the Ethics of Affiliated Hospital of Jiujiang University (20160214AHJUN3).

\section{Patient consent for publication}

Not applicable.

\section{Competing interests}

The authors declare that they have no competing interests.

\section{References}

1. Ueda P,Cnattingius S, Stephansson O, Ingelsson E, Ludvigsson JF and Bonamy AK: Cerebrovascular and ischemic heart disease in young adults born preterm: A population-based Swedish cohort study. Eur J Epidemiol 29: 253-260, 2014.

2. Su D, Riley J, Armstead WM and Liu R: Salvinorin A pretreatment preserves cerebrovascular autoregulation after brain hypoxic/ischemic injury via extracellular signal-regulated kinase/mitogen-activated protein kinase in piglets. Anesth Analg 114: 200-204, 2012.

3. Sorrentino E, Diedler J, Kasprowicz M, Budohoski KP, Haubrich C, Smielewski P, Outtrim JG, Manktelow A, Hutchinson PJ, Pickard JD, et al: Critical thresholds for cerebrovascular reactivity after traumatic brain injury. Neurocrit Care 16: 258-266, 2012.

4. Wang S, Yuan Y, Xia W, Li F, Huang Y, Zhou Y and Guo Y: Neuronal apoptosis and synaptic density in the dentate gyrus of ischemic rats' response to chronic mild stress and the effects of Notch signaling. PLoS One 7: e42828, 2012.

5. Atici A, Bozlu G, Turhan AH, Polat A, Nayci A, Okuyaz C and Taskinlar $\mathrm{H}$ : The role of trapidil on neuronal apoptosis in neonatal rat model of hypoxic ischemic brain injury. Early Hum Dev 84: 243-247, 2008.

6. Zhao J, Pei DS, Zhang QG and Zhang GY: Down-regulation $\mathrm{Cdc} 42$ attenuates neuronal apoptosis through inhibiting MLK3/JNK3 cascade during ischemic reperfusion in rat hippocampus. Cell Signal 19: 831-843, 2007.

7. Sompol P, Xu Y, Ittarat W, Daosukho $\mathrm{C}$ and St Clair D: NF-kappaB-associated MnSOD induction protects against beta-amyloid-induced neuronal apoptosis. J Mol Neurosci 29: 279-288, 2006.

8. Kaltschmidt B, Uherek M, Wellmann H, Volk B and Kaltschmidt C: Inhibition of NF-kappaB potentiates amyloid beta-mediated neuronal apoptosis. Proc Natl Acad Sci USA 96: 9409-9414, 1999.

9. Lv J, Jia R, Yang D, Zhu J and Ding G: Candesartan attenuates Angiotensin II-induced mesangial cell apoptosis via TLR4/MyD88 pathway. Biochem Biophys Res Commun 380: 81-86, 2009.
10. Ha T, Hua F, Li Y, Ma J, Gao X, Kelley J, Zhao A, Haddad GE, Williams DL, Browder IW, et al: Blockade of MyD88 attenuates cardiac hypertrophy and decreases cardiac myocyte apoptosis in pressure overload-induced cardiac hypertrophy in vivo. Am J Physiol Heart Circ Physiol 290: H985-H994, 2006.

11. Han KJ, Su X, Xu LG, Bin LH, Zhang J and Shu HB: Mechanisms of the TRIF-induced interferon-stimulated response element and NF-kappaB activation and apoptosis pathways. J Biol Chem 279: 15652-15661, 2004.

12. Ramadan WH and Kabbara WK: Sitagliptin/Simvastatin: A first combination tablet to treat type 2 diabetes and hypercholesterolemia-a review of its characteristics. Vasc Health Risk Manag 11: 125-132, 2015.

13. Taveira-DaSilva AM, Jones AM, Julien-Williams PA, Stylianou M and Moss J: Retrospective review of combined sirolimus and simvastatin therapy in lymphangioleiomyomatosis. Chest 147: 180-187, 2015.

14. Karki K, Knight RA, Han Y, Yang D, Zhang J, Ledbetter KA, Chopp M and Seyfried DM: Simvastatin and atorvastatin improve neurological outcome after experimental intracerebral hemorrhage. Stroke 40: 3384-3389, 2009.

15. Morishita S, Oku H, Horie T, Tonari M, Kida T, Okubo A, Sugiyama T, Takai S, Hara H and Ikeda T: Systemic simvastatin rescues retinal ganglion cells from optic nerve injury possibly through suppression of astroglial NF- $\mathrm{kB}$ activation. PloS One 9: e84387, 2014.

16. Park DS, So HS, Lee JH, Park HY, Lee YJ, Cho JH, Yoon KH, Park C, Yun K and Park R: Simvastatin treatment induces morphology alterations and apoptosis in murine cochlear neuronal cells. Acta Otolaryngol 129: 166-174, 2009.

17. Leitmeyer K, Glutz A, Setz C, Wieland L, Egloff S, Bodmer D and Brand Y: Simvastatin results in a dose-dependent toxic effect on spiral ganglion neurons in an in vitro organotypic culture assay. Biomed Res Int 2016: 3580359, 2016.

18. Zhao Y, Pan R, Li S, Luo Y, Yan F, Yin J, Qi Z, Yan Y, Ji X and Liu KJ: Chelating intracellularly accumulated zinc decreased ischemic brain injury through reducing neuronal apoptotic death. Stroke 45: 1139-1147, 2014.

19. Wang Q, Zengin A, Deng C, Li Y, Newell KA, Yang GY, Lu Y, Wilder-Smith EP, Zhao H and Huang XF: High dose of simvastatin induces hyperlocomotive and anxiolytic-like activities: The association with the up-regulation of NMDA receptor binding in the rat brain. Exp Neurol 216: 132-138, 2009.

20. Walker TL and Kempermann G: One mouse, two cultures: Isolation and culture of adult neural stem cells from the two neurogenic zones of individual mice. J Vis Exp 25: e51225, 2014.

21. Wu X, Gowda NM, Kawasawa YI and Gowda DC: A malaria protein factor induces IL-4 production by dendritic cells via PI3K-Akt-NF- $\kappa \mathrm{B}$ signaling independent of MyD88/TRIF and promotes Th2 response. J Biol Chem 293: 10425-10434, 2018.

22. Livak KJ and Schmittgen TD: Analysis of relative gene expression data using real-time quantitative PCR and the 2(-Delta Delta C(T)) method. Methods 25: 402-408, 2001.

23. Park JS, Kim S, Han DK, Lee JY and Ghil SH: Isolation of neural precursor cells from skeletal muscle tissues and their differentiation into neuron-like cells. Exp Mol Med 39: 483-490, 2007.

24. Meyrat BJ, Tercier S, Lutz N, Rilliet B, Forcada-Guex M and Vernet O: Introduction of a urodynamic score to detect pre- and postoperative neurological deficits in children with a primary tethered cord. Childs Nerv Syst 19: 716-721, 2003.

25. McBride DW, Nowrangi D, Kaur H, Wu G, Huang L, Lekic T, Tang $\mathrm{J}$ and Zhang JH: A composite neurobehavioral test to evaluate acute functional deficits after cerebellar haemorrhage in rats. J Cereb Blood Flow Metab 38: 433-446, 2018.

26. Gamberini MT, Rodrigues DS, Rodrigues D and Pontes VB: Effects of the aqueous extract of Pimpinella anisum L. seeds on exploratory activity and emotional behavior in rats using the open field and elevated plus maze tests. J Ethnopharmacol 168: 45-49, 2015.

27. Annunziata I, Patterson A and d'Azzo A: Isolation of mitochondria-associated ER membranes (MAMs) and glycosphingolipid-enriched microdomains (GEMs) from brain tissues and neuronal cells. Methods Mol Biol 1264: 25-33, 2015.

28. Hijioka M, Matsushita H, Hisatsune A, Isohama $\mathrm{Y}$ and Katsuki $\mathrm{H}$ : Therapeutic effect of nicotine in a mouse model of intracerebral hemorrhage. J Pharmacol Exp Ther 338: 741-749, 2011. 
29. Tong LS, Shao AW, Ou YB, Guo ZN, Manaenko A, Dixon BJ, Tang J, Lou M and Zhang JH: Recombinant Gas6 augments Axl and facilitates immune restoration in an intracerebral hemorrhage mouse model. J Cereb Blood Flow Metab 37: 1971-1981, 2017.

30. Zhang G, Li M, Xu Y, Peng L, Yang C, Zhou Y and Zhang J: Antioxidation effect of simvastatin in aorta and hippocampus: A rabbit model fed high-cholesterol diet. Oxid Med Cell Longev 2016: 6929306, 2016.

31. Metais C, Hughes B and Herron CE: Simvastatin increases excitability in the hippocampus via a PI3 kinase-dependent mechanism. Neuroscience 291: 279-288, 2015.

32. Lin S, Yin Q, Zhong Q, Lv FL, Zhou Y, Li JQ, Wang JZ, Su BY and Yang QW: Heme activates TLR4-mediated inflammatory injury via MyD88/TRIF signaling pathway in intracerebral hemorrhage. J Neuroinflammation 9: 46, 2012.

33. Shabanzadeh AP, Shuaib A and Wang CX: Simvastatin reduced ischemic brain injury and perfusion deficits in an embolic mode of stroke. Brain Res 1042: 1-5, 2005

34. Hayashi T, Hamakawa K, Nagotani S, Jin G, Li F, Deguchi K, Sehara Y, Zhang H, Nagano I, Shoji M and Abe K: HMG CoA reductase inhibitors reduce ischemic brain injury of Wistar rats through decreasing oxidative stress on neurons. Brain Res 1037: 52-58, 2005.

35. Hadi NR, Al-Amran F, Yousif M and Zamil ST: Antiapoptotic effect of simvastatin ameliorates myocardial ischemia/reperfusion injury. ISRN Pharmacol 2013: 815094, 2013.

36. Montaner J,Bustamante A, Garcia-Matas S,Martínez-ZabaletaM, Jiménez C, de la Torre J, Rubio FR, Segura T, Masjuán J, Cánovas D, et al: Combination of thrombolysis and statins in acute stroke is safe: Results of the STARS randomized trial (stroke treatment with acute reperfusion and simvastatin). Stroke 47: 2870-2873, 2016.

37. Chen G, Zhang S, Shi J, Ai J, Qi M and Hang C: Simvastatin reduces secondary brain injury caused by cortical contusion in rats: Possible involvement of TLR4/NF-kappaB pathway. Exp Neurol 216: 398-406, 2009.

38. Wu H, Mahmood A, Lu D, Jiang H, Xiong Y, Zhou D and Chopp M: Attenuation of astrogliosis and modulation of endothelial growth factor receptor in lipid rafts by simvastatin after traumatic brain injury. J Neurosurg 113: 591-597, 2010 .
39. Wang H, Lynch JR, Song P, Yang HJ, Yates RB, Mace B, Warner DS, Guyton JR and Laskowitz DT: Simvastatin and atorvastatin improve behavioral outcome, reduce hippocampal degeneration, and improve cerebral blood flow after experimental traumatic brain injury. Exp Neurol 206: 59-69, 2007.

40. Balduini W, De Angelis V, Mazzoni E and Cimino M: Simvastatin protects against long-lasting behavioral and morphological consequences of neonatal hypoxic/ischemic brain injury. Stroke 32: 2185-2191, 2001.

41. Yang D, Knight RA, Han Y, Karki K, Zhang J, Ding C, Chopp M and Seyfried DM: Vascular recovery promoted by atorvastatin and simvastatin after experimental intracerebral hemorrhage: Magnetic resonance imaging and histological study. J Neurosurg 114: 1135-1142, 2011.

42. Zhao XH, Xu ZR, Zhang Q and Yang YM: Simvastatin protects human osteosarcoma cells from oxidative stress-induced apoptosis through mitochondrial-mediated signaling. Mol Med Rep 5: 483-488, 2012.

43. Chaudhry K, Rogers R, Guo M, Lai Q, Goel G, Liebelt B, Ji X, Curry A, Carranza A, Jimenez DF and Ding Y: Matrix metalloproteinase-9 (MMP-9) expression and extracellular signal-regulated kinase 1 and 2 (ERK1/2) activation in exercise-reduced neuronal apoptosis after stroke. Neurosci Lett 474: 109-114, 2010.

44. Wen S, Li H, Wu ML, Fan SH, Wang Q, Shu XH, Kong QY, Chen $\mathrm{XY}$ and Liu J: Inhibition of NF- $\mathrm{KB}$ signaling commits resveratrol-treated medulloblastoma cells to apoptosis without neuronal differentiation. J Neurooncol 104: 169-177, 2011.

45. Cates EA, Connor EE, Mosser DM and Bannerman DD: Functional characterization of bovine TIRAP and MyD88 in mediating bacterial lipopolysaccharide-induced endothelial NF-kappaB activation and apoptosis. Comp Immunol Microbiol Infect Dis 32: 477-490, 2009.

46. Kaiser WJ and Offermann MK: Apoptosis induced by the toll-like receptor adaptor TRIF is dependent on its receptor interacting protein homotypic interaction motif. J Immunol 174: 4942-4952, 2005.

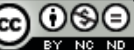

This work is licensed under a Creative Commons Attribution-NonCommercial-NoDerivatives 4.0 International (CC BY-NC-ND 4.0) License. 